\title{
Clinical Anatomy of the Liver: Review of the 19th Meeting of the Japanese Research Society of Clinical Anatomy
}

\author{
Yoshihiro Sakamoto $^{\text {a }}$ Norihiro Kokudo $^{a}$ Yoshikuni Kawaguchia \\ Keiichi Akita ${ }^{b}$ \\ ${ }^{a}$ Hepato-Biliary-Pancreatic Surgery Division, Artificial Organ and Transplantation Division,

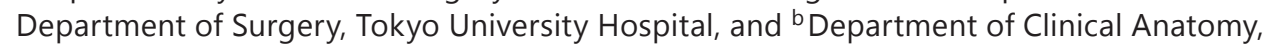 \\ Tokyo Medical and Dental University, Tokyo, Japan
}

\section{Key Words}

Couinaud's segment · Glissonean approach · Segmentectomy of the liver · Indocyanine green $\cdot$ Caudate lobe $\cdot$ Donor hepatectomy

\begin{abstract}
Precise clinical knowledge of liver anatomy is required to safely perform a hepatectomy, for both open and laparoscopic surgery. At the 19th meeting of the Japanese Research Society of Clinical Anatomy (JRSCA), we conducted special symposia on essential issues of liver surgery, such as the history of hepatic segmentation, the glissonean pedicle approach, application of 3-D imaging simulation and fluorescent imaging using indocyanine green solution, a variety of segmentectomies including caudate lobectomy, the associating liver partition and portal vein embolization for stage hepatectomy and harvesting liver grafts for living donor liver transplantation. The present review article provides useful information for liver surgeons and anatomic researchers.

(C) 2016 S. Karger AG, Basel
\end{abstract}

\section{Introduction}

The 19th meeting of the Japanese Research Society of Clinical Anatomy (JRSCA) was held at Sanjo-Kaikan (Hilltop Hall) at the University of Tokyo on November 14, 2015. The program consisted of two symposia on clinical anatomy of the liver, which included general remarks and specific information, one symposium on pancreatic anatomy for safe and precise pancreatectomy, a plenary session and other oral sessions on clinical anatomy for hepatobiliary and pancreatic surgery, plastic surgery and oral-maxillofacial surgery. 
Sakamoto et al.: Clinical Anatomy of the Liver: Review of the 19th Meeting of the Japanese Research Society of Clinical Anatomy

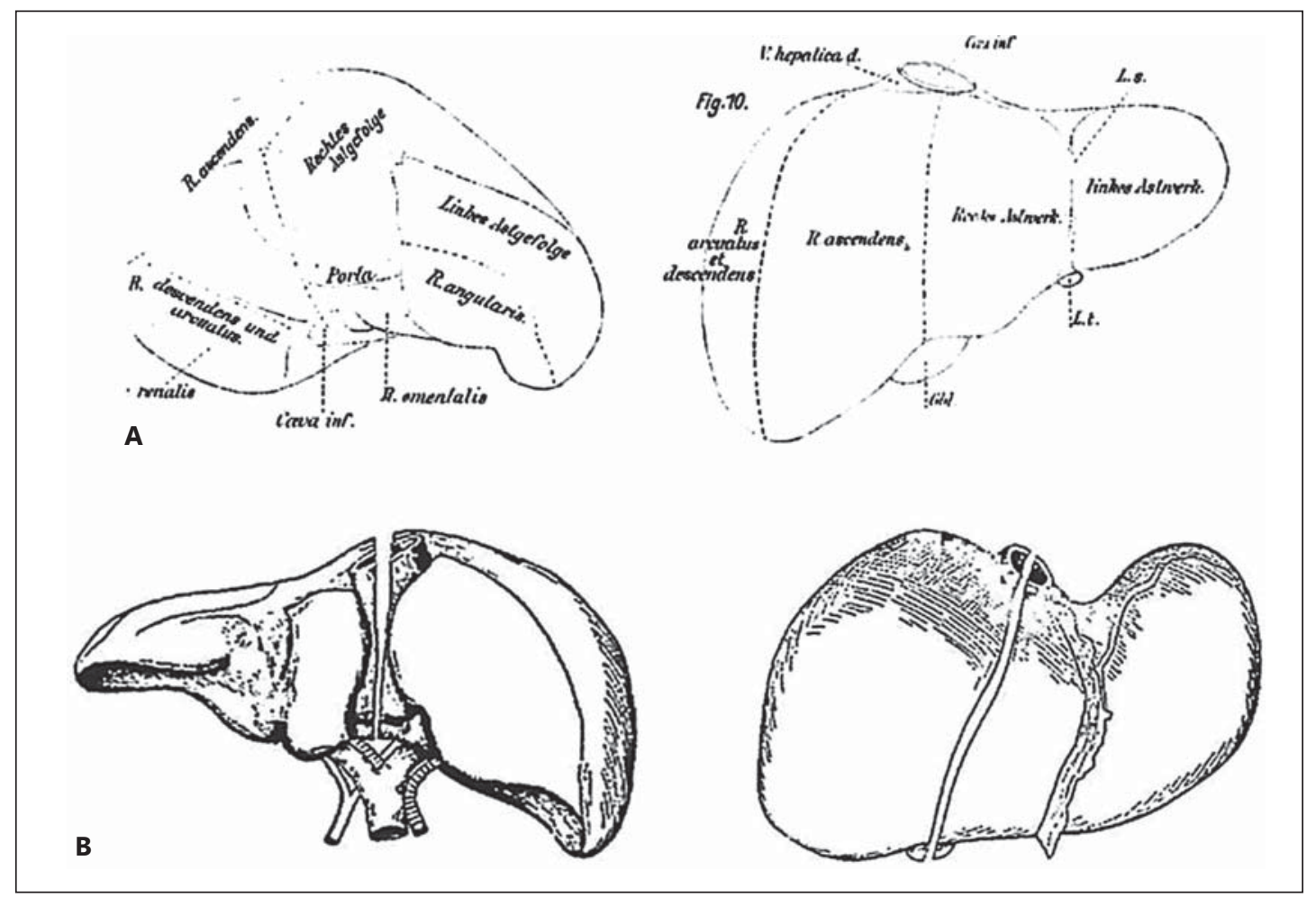

Fig. 1. A Segmentation of the liver proposed by Rex [1]. B Segmentation of the liver proposed by Cantlie [2].

In this review article, the presentations which were provided in the two symposia on clinical anatomy of the liver are summarized to further the understanding of hepatic anatomy for the clinical application of safe hepatic surgery.

\section{General Remarks: Anatomy of the Liver}

\section{History of Hepatic Segmentation (Presented by Junichi Shindoh)}

The history of anatomical liver segmentation began at the end of the 15th century, with morphological observations of its external shape, and evolved over 400 years toward the modern concept of liver segmentation. Since then, Rex (1888), Cantlie (1898) and Serege (1901) classified the liver into left and right sides. Rex, in 1888, advocated the concept of the hemiliver based on the anatomy of the portal venous system, and found that the boundary between the right and left hemilivers is located on the line connecting the gallbladder bed and the inferior vena cava (IVC), and the middle hepatic vein (MHV) indicates the position of the intersegmental plane (fig. 1A) [1]. Cantlie independently found the same anatomical characteristics of the liver and predicted clinical application of these segmental characteristics for bleeding control during hepatectomy or portal vein ligation. Therefore, the intersegmental line between either side of the hemiliver has been called 'Rex-Cantlie's line' (fig. 1B) [2].

The intersegmental borders within the liver were then classified by Hjortsjö (1948), Healey (1953) and Couinaud (1954) et al. In 1951, Hjortsjö classified the liver into 6 parts: 3 on the right side and 3 on the left side [3]. Healey and Schroy established the current basic concept of gross liver segmentation, which consists of the left lateral, medial, anterior and 


\section{Liver Cancer}

\begin{tabular}{l|l}
\hline Liver Cancer 2017;6:146-160 \\
\hline DOI: 10.1159/000449490 & $\begin{array}{l}\text { @ 2016 S. Karger AG, Basel } \\
\text { www.karger.com/lic }\end{array}$ \\
\hline
\end{tabular}

Sakamoto et al.: Clinical Anatomy of the Liver: Review of the 19th Meeting of the Japanese Research Society of Clinical Anatomy
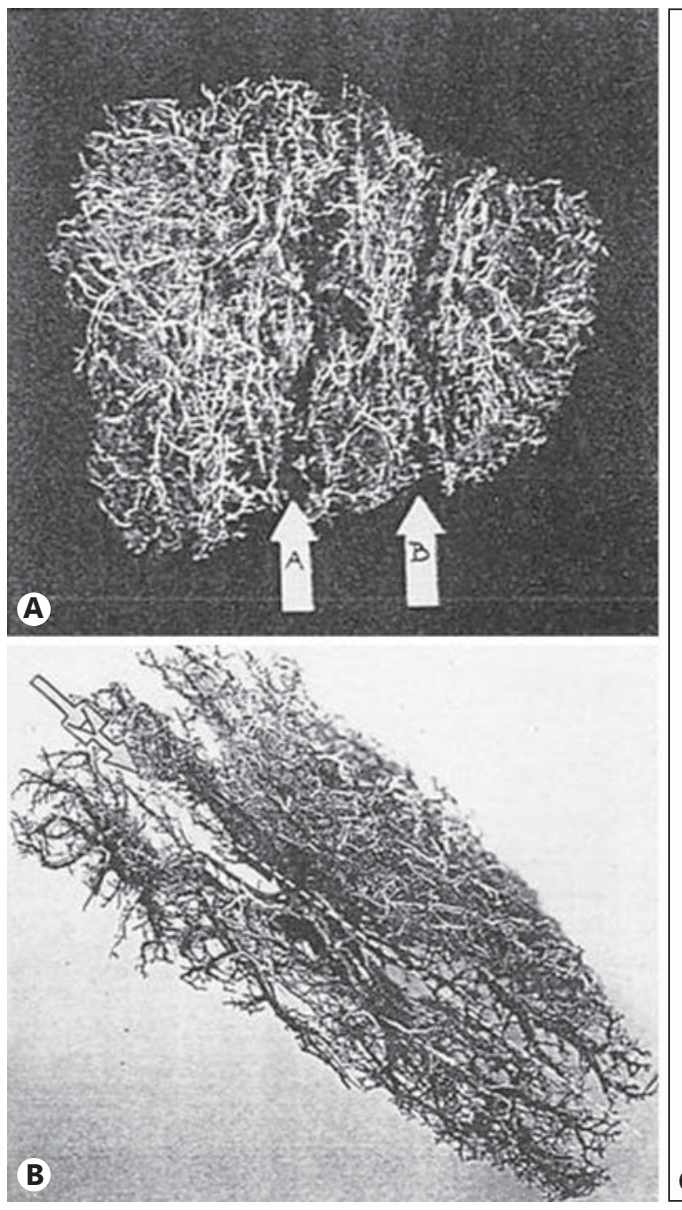

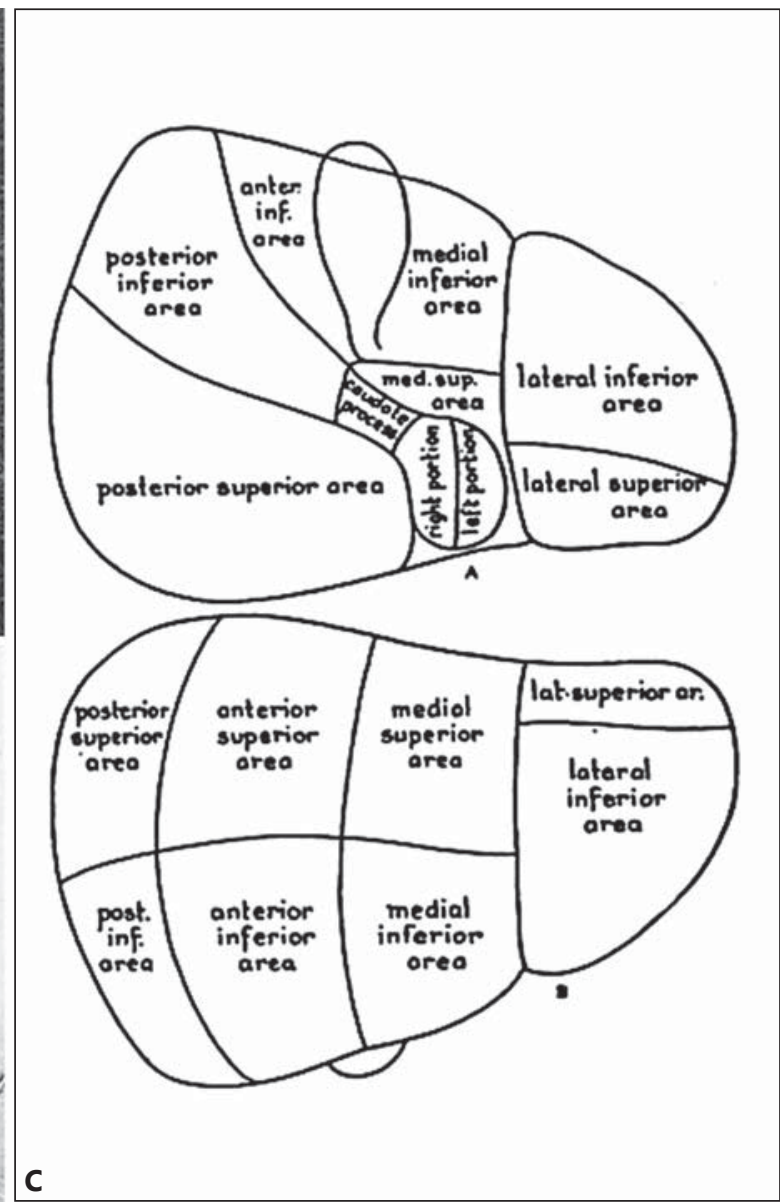

Fig. 2. A Arrow A indicates the boundary between the anterior and medial areas. Arrow B indicates the boundary between the lateral and the medial areas [4]. B Arrow A indicates the boundary between the anterior and the posterior areas [4]. C Segmentation of the liver by Healey and Schroy [4].

posterior areas. In 1953, Healey and Schroy further divided each area into 2 parts, using 100 cast models of biliary trees (fig. 2) [4]. His findings were used by Couinaud in 1954 to further the concept of liver segmentation into 8 parts. Couinaud proposed clinically applicable liver segmentation for systemic liver surgery (fig. 3) [5].

\section{Glissonean Pedicle Approach (Presented by Masakazu Yamamoto)}

The first right hepatectomy was performed by Honjo in Japan in 1949, and then by LortatJacob in France in 1952. These hepatectomies were performed after division of the right hepatic artery and portal vein individually in the glissonean sheath, which is called the controlled method. On the other hand, in the glissonean approach, the glissonean pedicle can be secured and divided without dissection of each vascular anatomy in the hepatoduodenal ligament. The intrahepatic Glissonean approach was first reported by Lin in Taiwan (1960) and Tung in Vietnam (1962). The extrahepatic Glissonean approach was introduced by Couinaud (1985) and Takasaki (1986) [6] (fig. 4) and is applied to laparoscopic anatomical hepatectomy. The root of the third order branches of the glissonean pedicles can be secured by approaching via the hepatic hilum after securing the second order glissonean pedicles, which is defined as corn unit resection (fig. 5). 


\section{Liver \\ Cancer}

Fig. 3. Couinaud's segmentation of the liver [5].

Fig. 4. Takasaki's concept of liver segmentation [6].

Fig. 5. The concept of cone unit resection indicates anatomical resection based on segments that are smaller than Couinaud's segments.

\begin{tabular}{l|l}
\hline \multicolumn{2}{l|}{ Liver Cancer 2017;6:146-160 } \\
\hline DOI: 10.1159/000449490 & $\begin{array}{l}\text { @ 2016 S. Karger AG, Basel } \\
\text { www.karger.com/lic }\end{array}$ \\
\hline
\end{tabular}

Sakamoto et al.: Clinical Anatomy of the Liver: Review of the 19th Meeting of the Japanese Research Society of Clinical Anatomy
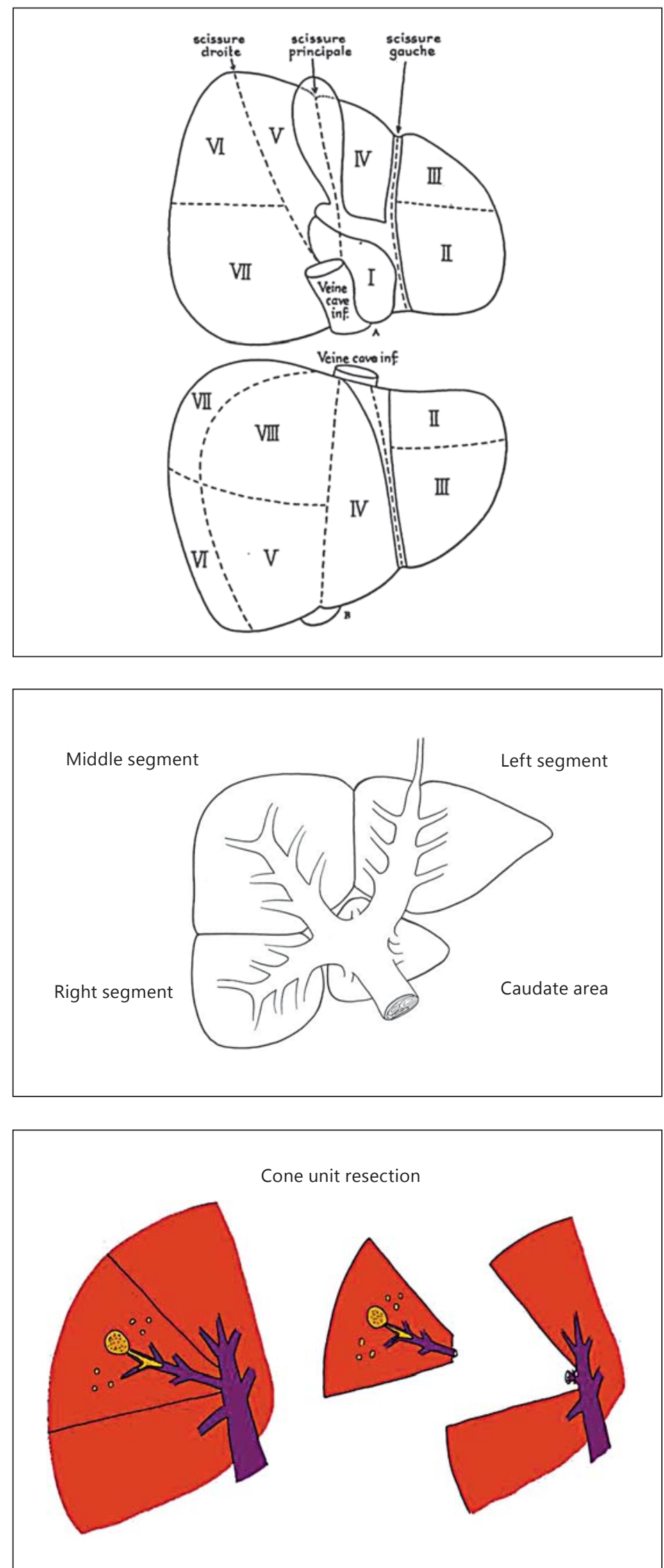

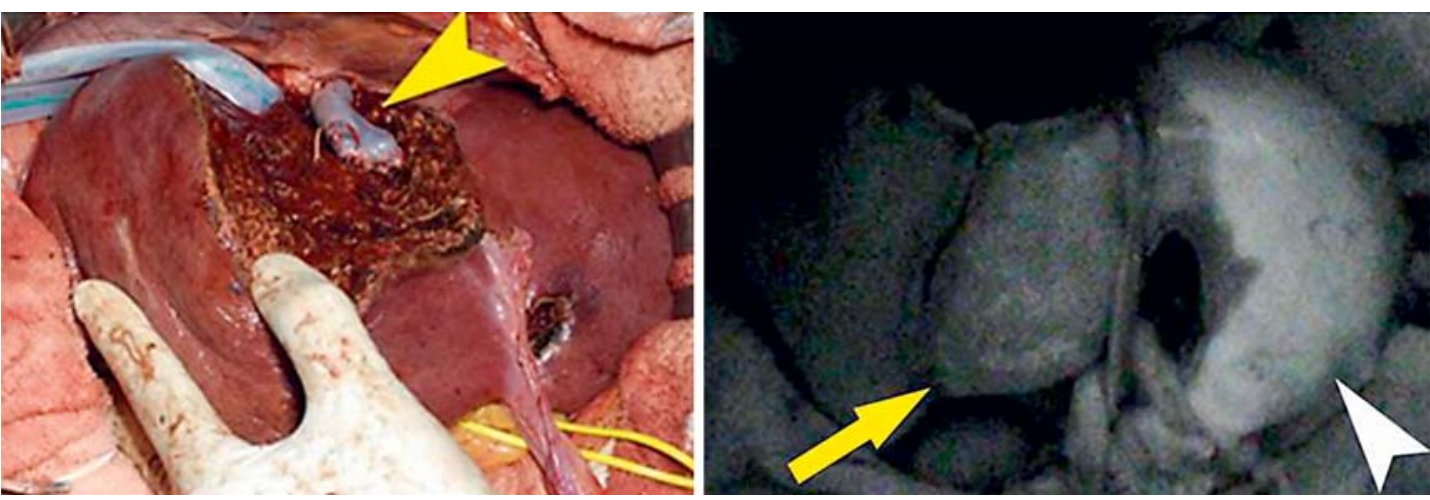

Fig. 6. The left hepatic vein was reconstructed (yellow arrowhead) after division of the left and middle hepatic veins, and fluorescence intensity in the reconstructed left hepatic vein territories (white arrowhead, non-veno-occlusive regions) is higher than that in the divided MHV territories (arrow, veno-occlusive regions).

Identification of Veno-Occlusive Hepatic Regions Using Fluorescence Imaging (Presented by Yoshikuni Kawaguchi)

The intraoperative identification method and functional evaluation for veno-occlusive regions have yet to be established. Kawaguchi used the indocyanine green (ICG)-fluorescence imaging technique to study 45 patients and 18 donors who developed venous occlusion in the remnant livers. Veno-occlusive regions were identified as being territories with lower fluorescence intensity than non-veno-occlusive regions [fig. 6; median (range), 99 (39-173) vs. 182 (71-255), respectively, $\mathrm{p}<0.001$ ]. The portal uptake of ICG in veno-occlusive regions decreased to approximately $40 \%$ of that in non-veno-occlusive regions. The ICG concentration ratio of veno-occlusive regions to non-veno-occlusive regions (median \pm standard deviation) was $0.36 \pm 0.17$.

Boundary between the Drainage Areas of the Middle and Right Hepatic Vein (Presented by Shouichi Sato)

It is well known that the major hepatic veins run along the liver segment borders, but there are few studies on the drainage area of the hepatic vein and its boundary.

Cho et al. [7, 8] advocated the concept of the 'anterior fissure', where the anterior segment is divided into ventral and dorsal subsegments. They also proposed that the anterior fissure coincides with the boundary between the drainage area of the MHV and the right hepatic vein (RHV). However, their proposition seems inconsistent because the anterior fissure vein (AFV) runs along anterior fissure and mainly flows into the MHV and sometimes into the RHV.

To investigate the boundary between the MHV and RHV, we assessed computed tomography (CT) data from 32 living liver donors using three-dimensional simulation software (OVA; Hitachi Medico). The AFV flows into the MHV ( $n=24$, group M) and the RHV ( $n=6$, group R). In the other 2 donors (group MR), there were two AFVs that separately flow into the MHV and RHV.

In all donors, the anterior portal branch ran along the boundary plane between the drainage area of the MHV and RHV. In group M, the dorsal branch of the portal vein ran along the boundary (fig. 7). In contrast, the ventral branch of the portal vein ran along the boundary in group R. In group MR, both the ventral and dorsal branches partially ran along the boundary. The findings are summarized in figure 8 . The boundary line on the liver 


\section{Liver Cancer}

Fig. 7. The drainage area of the RHV is transparentized. The anterior portal vein and the P8 ventral branch run along the boundary plane between MHV and RHV.

\begin{tabular}{l|l}
\hline Liver Cancer 2017;6:146-160 \\
\hline DOI: 10.1159/000449490 & $\begin{array}{l}\text { @ 2016 S. Karger AG, Basel } \\
\text { www.karger.com/lic }\end{array}$ \\
\hline
\end{tabular}

Sakamoto et al.: Clinical Anatomy of the Liver: Review of the 19th Meeting of the Japanese Research Society of Clinical Anatomy

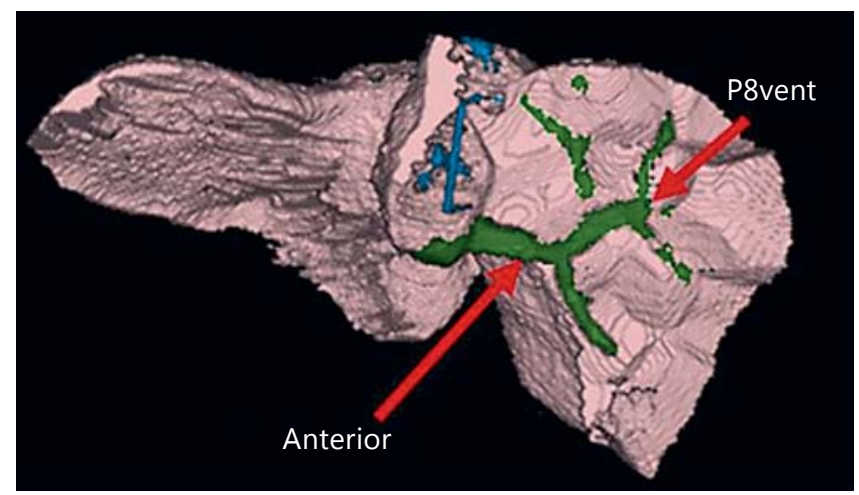

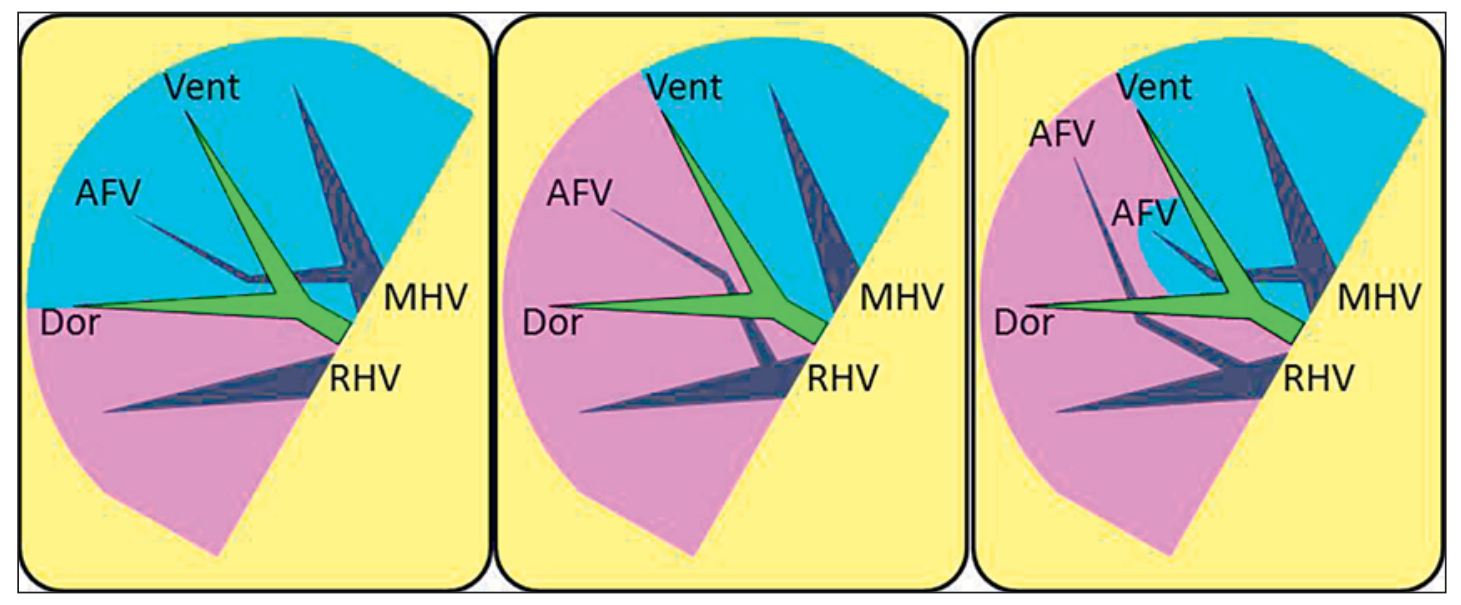

Fig. 8. A diagram of the relationship between the hepatic veins and the anterioportal branch. The main trunk of the anterior portal vein runs along the boundary between the drainage area of the MHV and RHV. When the AFV is a tributary of the MHV, the dorsal branch of the portal vein runs along the boundary, and when the AFV is a tributary of the RHV, the ventral branch runs along the boundary. In a few cases of multiple AFVs, part of the anterior portal tributaries emerges on the boundary.

surface between the MHV and RHV drainage area did not coincide with the anterior fissure. In summary, the anterior portal vein and its tributaries run along the boundary plane between the MHV and RHV drainage areas. The boundary does not coincide with the anterior fissure.

\section{Delineation of Liver Anatomy during Laparoscopic Liver Resection Using}

Indocyanine-Fluorescence Imaging (Presented by Takeaki Ishizawa)

Laparoscopic hepatectomy has limitations for visual inspection and manual palpation. Ishizawa showed that fluorescence imaging can be applied more efficiently for laparoscopic hepatectomy. That is because surgeons do not need to turn their eyes from the operative field to a monitor as they do during open hepatectomy. ICG fluorescence imaging enables tumor identification and anatomic segment visualization (fig. 9) and, thus, is helpful to intraoperatively understand liver anatomy. 


\section{Liver Cancer}

\begin{tabular}{l|l}
\hline \multicolumn{2}{l}{ Liver Cancer 2017;6:146-160 } \\
\hline DOI: 10.1159/000449490 & $\begin{array}{l}\text { (C) 2016 S. Karger AG, Basel } \\
\text { www.karger.com/lic }\end{array}$ \\
\hline
\end{tabular}

Sakamoto et al.: Clinical Anatomy of the Liver: Review of the 19th Meeting of the Japanese Research Society of Clinical Anatomy
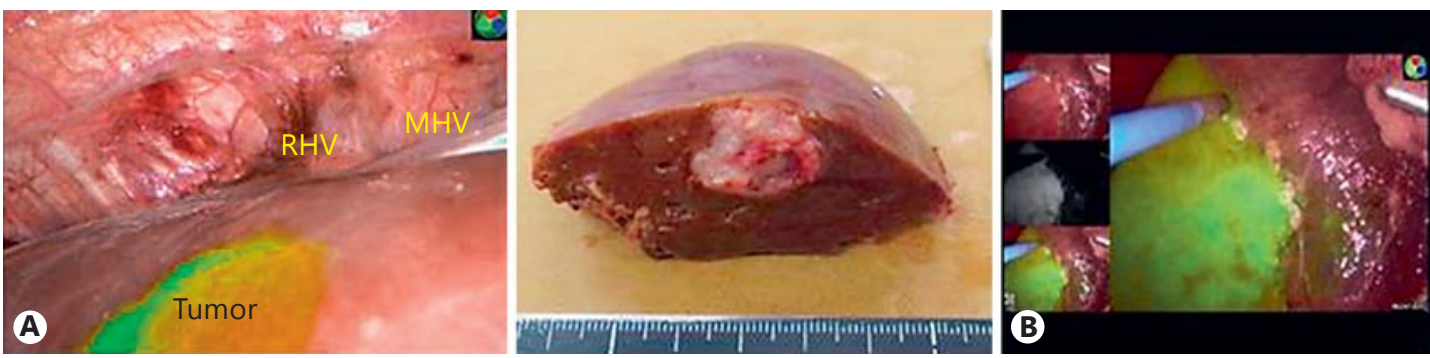

Fig. 9. A A tumor was identified on the liver surface as fluorescence during laparoscopic hepatectomy. B Segment 7 was visualized as a region with fluorescence while segment 6 was identified as a region without fluorescence.

\section{Specifics: Safe and Rational Hepatectomy Based on the Clinical Anatomy}

\section{Anatomy of the Caudate Lobe (Presented by Masamitsu Kumon)}

The anatomy or boundary of the caudate lobe has been discussed for several decades, and anatomical resection of the caudate lobe has been considered to be technically demanding compared with resection of other hepatic segments.

\section{Anatomy of the Caudate Lobe Based on the Study of Liver Casts (Presented by Masamitsu}

Kumon)

In the 1980s, Dr. Kumon began studies on liver anatomy, with a focus on the caudate lobe, when he was a resident at the National Cancer Center Hospital in Tokyo. He made 5 casts at the Cancer Center Hospital and found that the caudate lobe had several branches from the first-order branch of the portal veins and hepatic arteries at the hepatic hilum. In the liver casts, blue, red and yellow silicon rubber was injected in the portal, arterial and biliary systems. The caudate lobe was classified into three parts: the Spiegel lobe, the paracaval portion and the caudate process. Dr. Kumon continued his research at the Kochi Medical School in Kochi, Japan, and studied variations of the portal branches to the caudate lobe using a total of 23 liver casts [9].

Although the caudate lobe accounts for $2-10 \%$ of the total liver volume in adults, Dr. Kumon found that the volume of the caudate lobe was larger in the fetus, probably because the caudate branches have a direct relationship with the umbilical veins. The right-side boundary of the caudate lobe is controversial, but he showed that the caudate limbs should branch off the first branches of the portal veins (i.e. the right and left portal veins). In some cases, thick branches from the anterior portal pedicle run beside the IVC, but they cannot be defined as paracaval branches.

\section{Caudate Veins and Notch Found in Liver Casts (Presented by Kimitaka Kogure)}

The caudate vein was first described by Rex in 1888. In Japan, Dr. Arai in 1949 and Dr. Toyohara in 1954 used liver casts to show that the number of the caudate veins is $1-5$. In 1981, Dr. Nakamura classified the branching pattern of the short hepatic veins in the Spiegel lobe into 3 types [10]. Kogure revealed the relationship among the portal segmentation, proper caudate vein and the external notch of the caudate lobe using 88 liver casts. The notch of the caudate lobe was found in $54 \%$ of livers and had a close relationship with the portal segmentation of the caudate lobe and the proper caudate vein (i.e. the main venous branch in the caudate lobe) [11] (fig. 10). He further studied the hepatic veins on the border between 


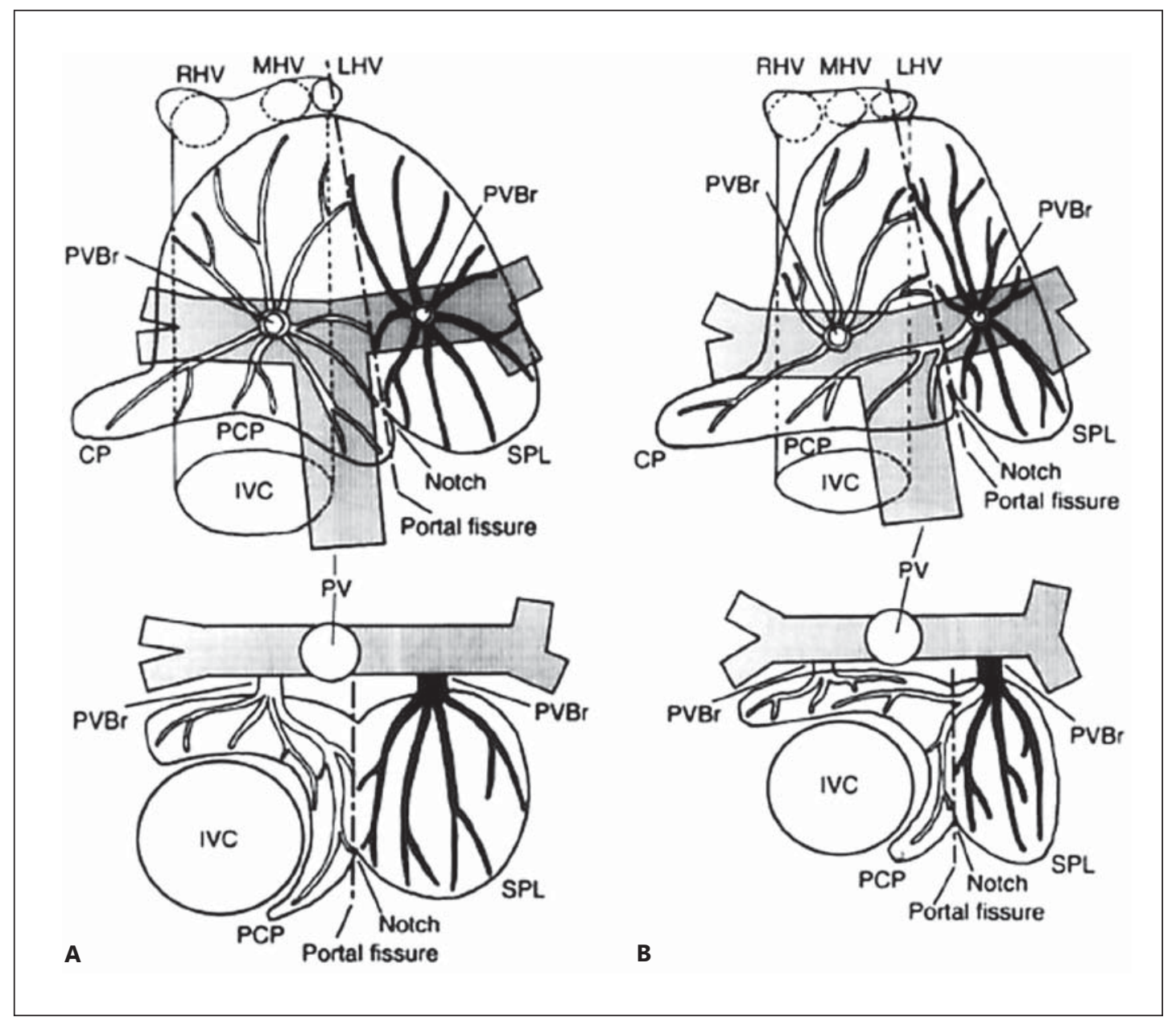

Fig. 10. Portal branches to the Spiegel lobe, paracaval portion, and caudate process divided by the notch of the liver [11]. A The caudate processus branches originate from the right portal vein. B The caudate processus branches originate from the left portal vein.

the caudate lobe and the right liver using 54 liver casts, and found 3 types of hepatic veins running into the IVC or the inferior RHV [12] (fig. 11).

The Right-Side Boundary of the Caudate Lobe (Presented by Harufumi Maki)

The boundary of the caudate lobe and the right liver is controversial. Maki studied the right-side boundary of the caudate lobe using 3-D simulation customized with CT images of 67 liver transplant donors. He found that on the right-side boundary of the caudate lobe, a small paracaval vein runs along the boundary of the caudate lobe in $89 \%$ of livers in addition to the RHV vein, inferior RHV and caudate processus hepatic vein, as defined by Kogure (fig. 12).

Clinical Anatomy Requisite for Caudate Lobe Resection (Presented by Junji Yamamoto)

Knowledge of clinical anatomy of the caudate lobe, and especially the boundary of the caudate lobe between the surrounding structures, is required for precise and safe caudate resection. Three points can be raised: 


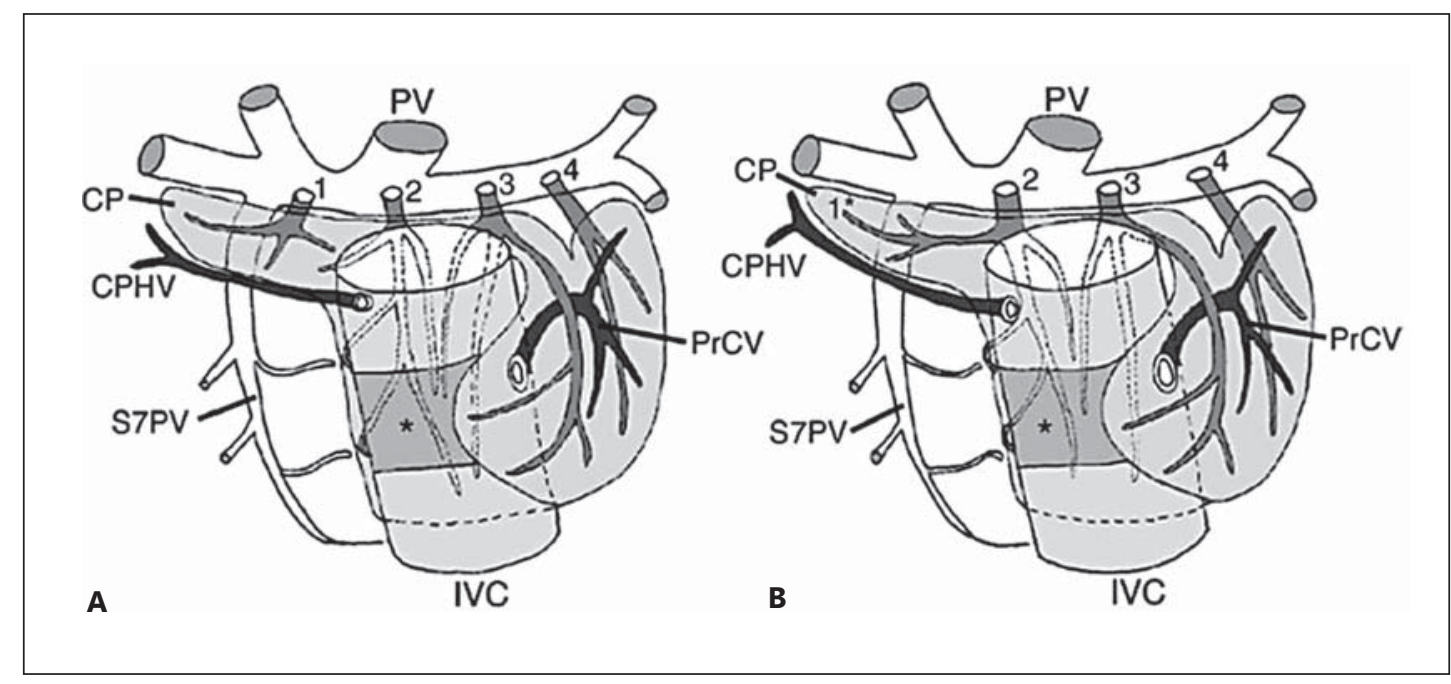

Fig. 11. Relationship between portal segmentation, proper caudate vein, and the external notch of the caudate lobe [12]. A An independent portal vein branch for the caudate processus is found. B A ramus of the portal vein branch for the paracaval portion of the caudate lobe covers the caudate processus.
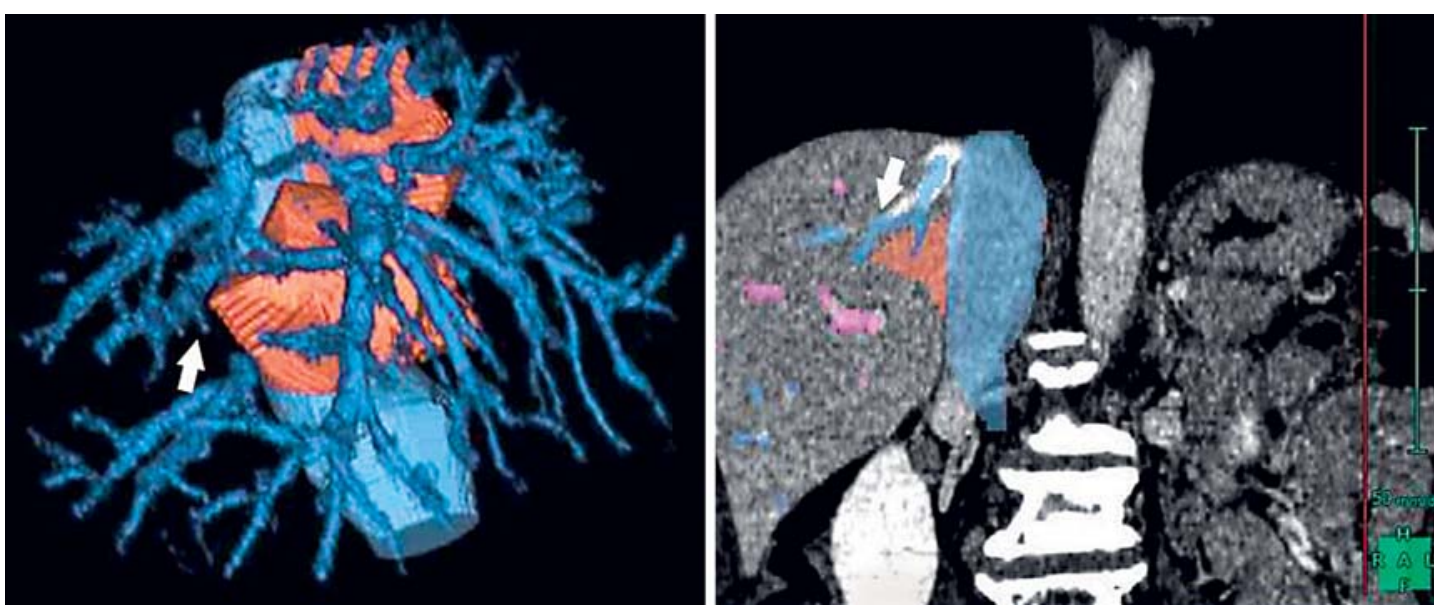

Fig. 12. The white arrow indicates a branch of the RHV which runs between the paracaval portion and the posterior segment of the liver using 3-D simulation that is customized with CT images of the liver.

Boundary with Other Hepatic Segments

The caudate hepatic artery supplies the dorsal part of the left medial segment in two thirds of the livers. During extended hemihepatectomy for hilar cholangiocarcinoma, some of the arterial branches from the caudate lobe are divided behind the MHV.

Dissection from the Hepatic Hilum

The ramification of the portal branches in the caudate lobe does not always coincide with that of biliary branches. Ninety percent of the Spiegel portal branches are from the left portal vein, while $50 \%$ of the portal branches in the caudate process are from the right portal vein. 


\section{Liver Cancer}

Fig. 13. A indicates the edge of the Spiegel lobe behind the IVC. B indicates the edge of the paracaval portion of the liver behind the IVC. The angle between A and B changes depending on the longitudinal location in each liver [13].

\begin{tabular}{l|l}
\hline Liver Cancer 2017;6:146-160 \\
\hline DOI: 10.1159/000449490 & $\begin{array}{l}\text { @ 2016 S. Karger AG, Basel } \\
\text { www.karger.com/lic }\end{array}$ \\
\hline
\end{tabular}

Sakamoto et al.: Clinical Anatomy of the Liver: Review of the 19th Meeting of the Japanese Research Society of Clinical Anatomy

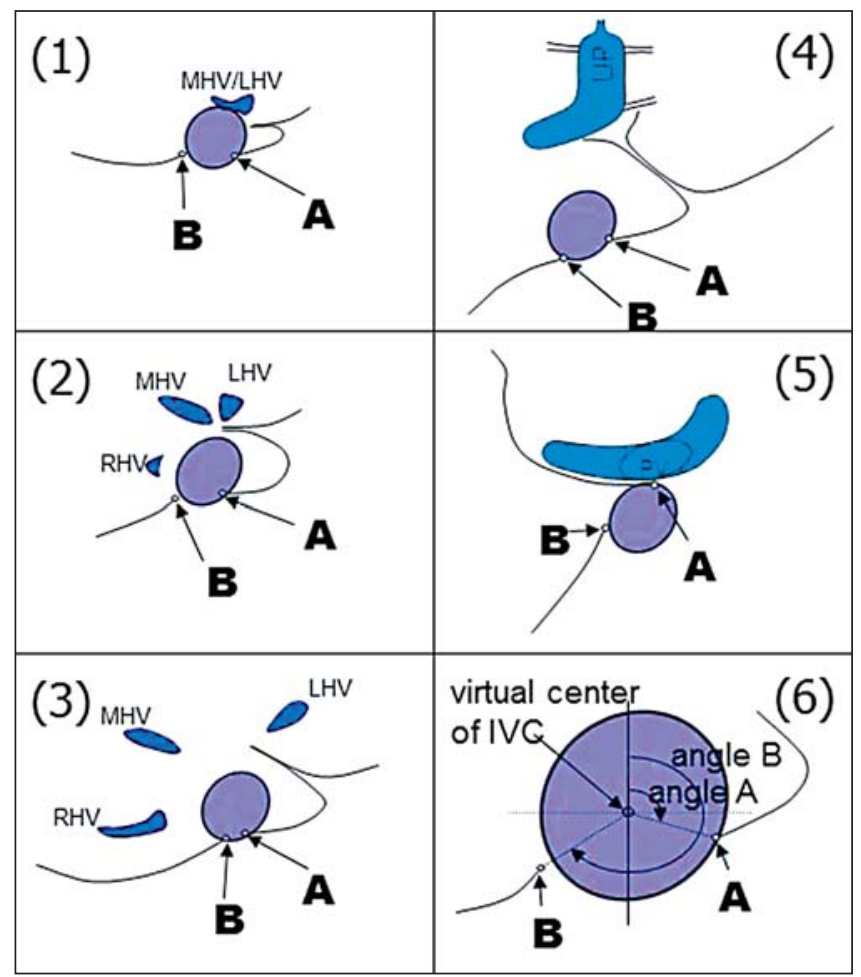

Dissection of the IVC

The thickest hepatic vein in the caudate lobe is located at the 1-2 o'clock position around the IVC. The Spiegel lobe surrounds the IVC beyond the dorsal midline in $20 \%$ of livers (fig. 13 and 14) [13].

\section{Anatomical Highlights of Left Trisectionectomy (Presented by Minoru Esaki)}

Left trisectionectomy is indicated in $11 \%$ of patients with perihilar cholangiocarcinoma and is associated with greater blood loss, longer operative time and more frequent surgical morbidity than conventional right or left hemihepatectomies (table 1) [14]. Based on the Japanese national registry, surgical mortality associated with this procedure was reported to be $12.1 \%$ in 2013 by the Japanese Society of Hepato-Biliary-Pancreatic Surgery, which was the highest mortality rate among all of the hepatectomy procedures.

Left trisectionectomy is associated with: (1) wider transactional area and greater blood loss; (2) less volume of the future liver remnant; (3) fewer bile duct orifices to be reconstructed compared with other hemihepatectomies; and (4) difficulty exposing and preserving the RHV, which is the only major hepatic vein that is preserved. However, in patients with an independent right posterior portal vein, division of the anterior and left portal vein is easy to accomplish, and hepaticojejunostomy can be performed more safely than in patients with conventional anatomy.

Important Points for Anatomical Resection of Segment 8 (Presented by Yoji Kishi)

Anatomical resection of Couinaud's segment can be recommended in patients with hepatocellular carcinoma. Anatomical resection of segment 8 (S8) consists of $28 \%$ of all the other segmentectomies, which shows that S8 is the most popular segment that is resected. S8 accounts for $24.2 \%$ of the entire liver volume, which is the largest segment [15]. 


\section{Liver \\ Cancer}

Fig. 14. The individual and locational change in the angle between $\mathrm{A}$ and $\mathrm{B}$ in the liver from fig. 13 [13].

\begin{tabular}{l|l}
\hline Liver Cancer 2017;6:146-160 \\
\hline DOI: 10.1159/000449490 & $\begin{array}{l}\text { @ 2016 S. Karger AG, Basel } \\
\text { www.karger.com/lic }\end{array}$ \\
\hline
\end{tabular}

Sakamoto et al.: Clinical Anatomy of the Liver: Review of the 19th Meeting of the Japanese Research Society of Clinical Anatomy

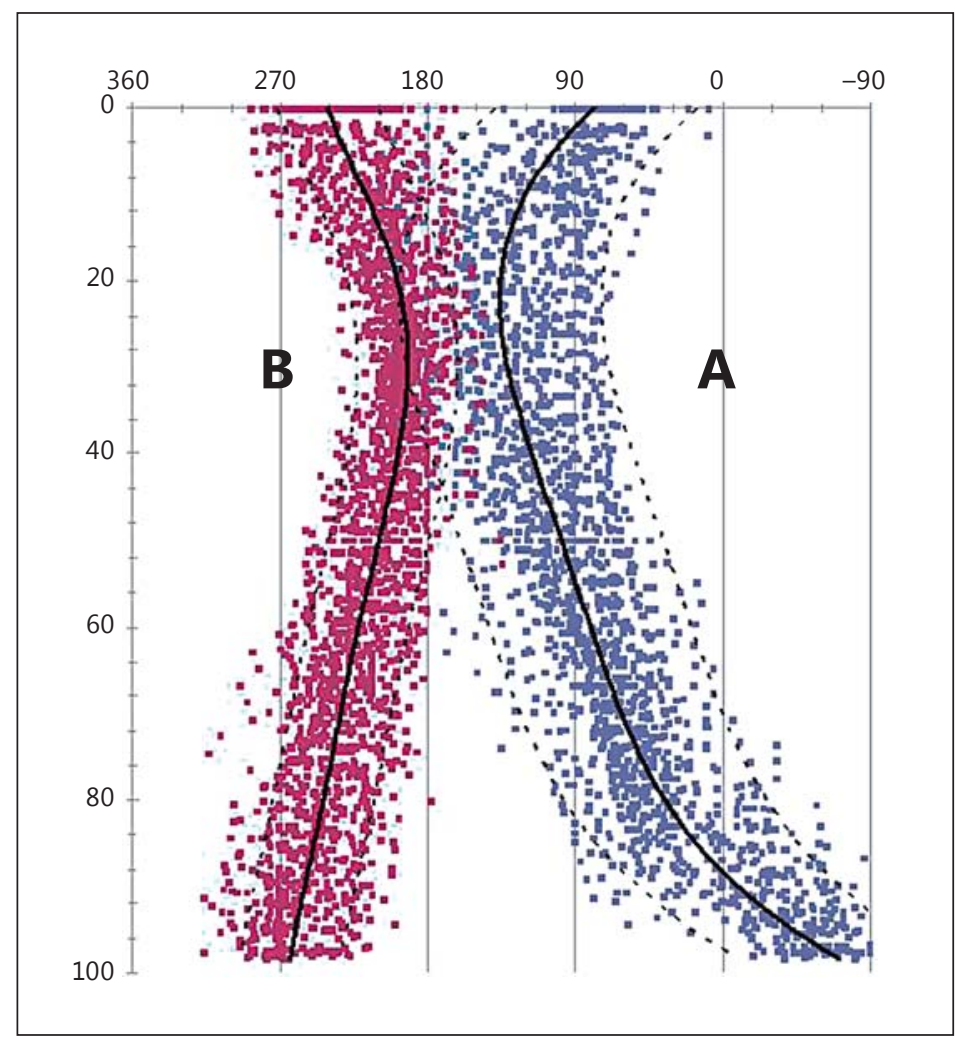

Table 1. Relationship between surgical procedures for the treatment of perihilar cholangiocarcinoma and outcomes

\begin{tabular}{|c|c|c|c|}
\hline & \multicolumn{2}{|c|}{ Hemihepatectomy } & \multirow{2}{*}{$\begin{array}{l}\text { Left trisectionectomy } \\
(n=31)\end{array}$} \\
\hline & right $(n=122)$ & left $(n=113)$ & \\
\hline $\begin{array}{l}\text { Portal vein embolizatic } \\
\text { performed }\end{array}$ & $98(80 \%)$ & $6(5 \%)$ & $22(71 \%)$ \\
\hline \multicolumn{4}{|l|}{ Combined resection } \\
\hline PVR & 22 & 17 & 3 \\
\hline HAR & 0 & 8 & 3 \\
\hline PVR + HAR & 0 & 9 & 2 \\
\hline PD & 14 & 4 & 0 \\
\hline \multicolumn{4}{|c|}{ Biliary orifices to be reconstructed } \\
\hline 1 & $27(22 \%)$ & $32(28 \%)$ & $18(58 \%)$ \\
\hline 2 & $57(47 \%)$ & $33(29 \%)$ & $10(32 \%)$ \\
\hline 3 or more & $38(31 \%)$ & $48(42 \%)$ & $3(10 \%)$ \\
\hline Operative time, $\min$ & 622 & 629 & 630 \\
\hline Blood loss, ml & 1,630 & 1,300 & 2,140 \\
\hline \multicolumn{4}{|l|}{ Complications } \\
\hline Grade IIIa or less & $56(46 \%)$ & $52(46 \%)$ & $23(74 \%)$ \\
\hline Grade IIIb or more & $8(7 \%)$ & $3(3 \%)$ & $1(3 \%)$ \\
\hline
\end{tabular}

PVR = Portal vein resection and reconstruction; HAR = hepatic artery resection and reconstruction; PD = pancreaticoduodenectomy. 


\section{Liver Cancer}

Fig. 15. Cut surface of the liver after anatomical resection of segment 8 of the liver. The forceps indicate the stumps of the ventral branches for segment 8.

\begin{tabular}{l|l}
\hline Liver Cancer 2017;6:146-160 \\
\hline DOI: 10.1159/000449490 & $\begin{array}{l}\text { @ 2016 S. Karger AG, Basel } \\
\text { www.karger.com/lic }\end{array}$ \\
\hline
\end{tabular}

Sakamoto et al.: Clinical Anatomy of the Liver: Review of the 19th Meeting of the Japanese Research Society of Clinical Anatomy

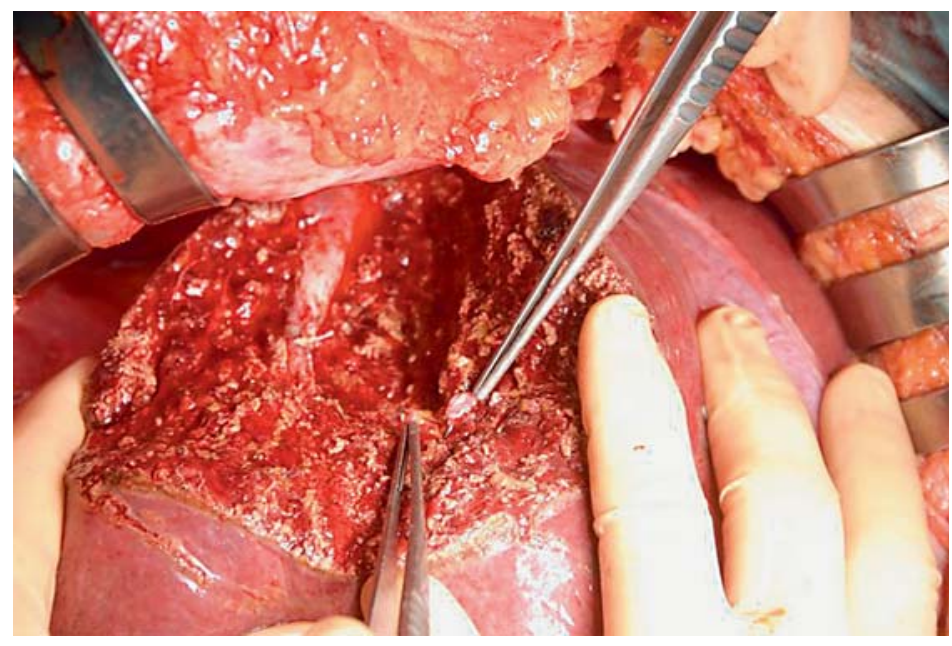

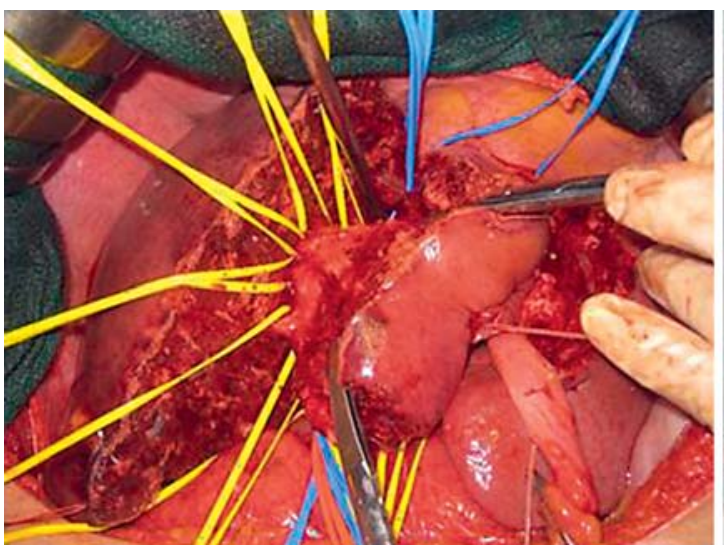

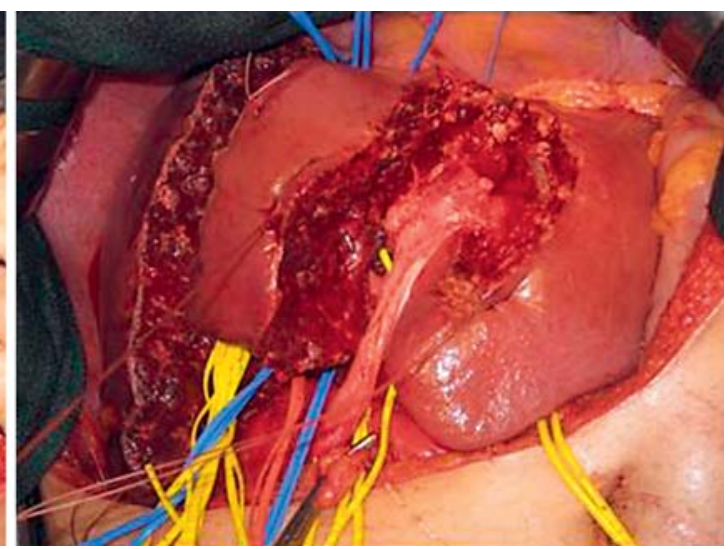

Fig. 16. Photo of the first stage of a modified ALPPS procedure preserving all the portal pedicles at the transection plane.

During anatomical resection of S8, the ventral and dorsal glissonean branches of segment 8 are divided, and the MHV and RHV are exposed on the transactional plane as the landmark veins. To reveal the boundary of S8, the dye injection method [16] and the counterstaining technique [17] are useful. However, it is sometimes difficult to use the glissonean approach to reach the root of G8. Recent introduction of dye-staining using ICG under fluorescence imaging facilitated the visualization of each segment even in livers with insufficient visualization of segments using conventional dye injection techniques [18].

After anatomical S8 resection, the landmark hepatic veins were exposed on the transactional area in 38\% of patients at the University of Tokyo Hospital [19] (fig. 15). The boundary between S8 and S5 is controversial, and the branching variants of the portal and biliary system do not always coincide [20].

\section{Arterial Anatomy Required for ALPPS (Presented by Kuniya Tanaka)}

A new two-stage hepatectomy, called associating liver partition and portal vein embolization for stage hepatectomy (ALPPS), to induce hypertrophy of the future liver remnant in patients with advanced hepatic malignancies has recently been developed in Germany [21]. 


\section{Liver Cancer}

Fig. 17. A A tricky anatomical variation during procurement of the RLS of the liver for LDLT. The right posterior hepatic artery runs behind the right anterior portal vein. B Accessory right anterior hepatic artery branching from A7. B1 The accessory hepatic artery was preserved, while A6 and A7 were reconstructed individually. B2 The accessory hepatic artery was divided, while the single posterior hepatic artery was reconstructed.

\begin{tabular}{l|l}
\hline Liver Cancer 2017;6:146-160 \\
\hline DOI: 10.1159/000449490 & $\begin{array}{l}\text { @ 2016 S. Karger AG, Basel } \\
\text { www.karger.com/lic }\end{array}$ \\
\hline
\end{tabular}

Sakamoto et al.: Clinical Anatomy of the Liver: Review of the 19th Meeting of the Japanese Research Society of Clinical Anatomy

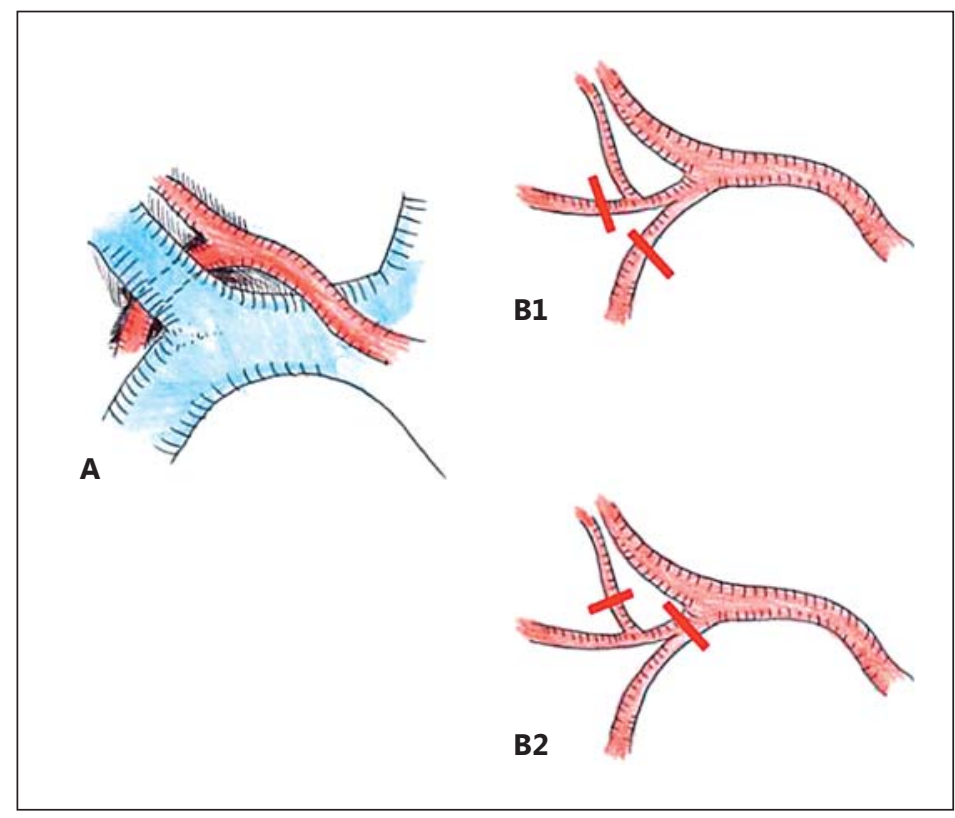

One complication associated with ALPPS is necrotic change of the de-vascularized liver segments after the first stage [22]. During conventional ALPPS, in which liver transection is performed just to the right of the falciform ligament, A4 is completely divided, and collateral arterial supply to segment 4 is key to avoid ischemic complications, but it is not always reliable. Therefore, Tanaka and colleagues proposed a modified ALPPS procedure that preserves all the portal pedicles at the transection plane (fig. 16). They found that the modified ALPPS provided comparable hypertrophy of the future liver remnant to the conventional ALPPS.

\section{Safety and Pitfalls of Using Right Lateral Sector Graft for a Living Donor Liver}

Transplantation (Presented by Takashi Kokudo)

Right lateral sector (RLS) grafting has contributed to the expansion of the donor pool for living donor liver transplantation (LDLT). At the University of Tokyo Hospital, 28 RLS grafts were used in 251 LDLTs between 2000 and 2013. Procurement of an RLS graft requires caution to dissect and cut the thinner hepatic artery, portal vein and bile duct compared with procurement of a conventional right or left liver graft. In donors with a supraportal hepatic artery, dissection of the thin hepatic artery between the right posterior portal vein and right posterior bile duct is technically demanding. This is more difficult in donors with a supraportal hepatic artery in segment 7 and infraportal hepatic artery in segment 6 (6.5\% in all donors; fig. 17A) [23]. Another concern for the bifurcation of the hepatic artery is donors in whom A8 branches from the posterior hepatic artery. Four donors who underwent procurement of an RLS graft at the University of Tokyo Hospital had this anomaly. Posttransplant hepatic artery thrombosis (HAT) occurred in two of the RLS grafts, and A6 and A7 were reconstructed individually to preserve A8 for the donor (fig. 17B1). However, no HAT occurred in two of the grafts in the posterior hepatic artery that was reconstructed when A8 was sacrificed. No ischemic complications occurred in these donors (fig. 17B2) [24]. 


\section{Liver Cancer}

\section{Conclusion}

Anatomical knowledge of the liver is essential for safe and precise liver surgery. Hepatic segmentation has been proposed by many researchers, and Couinaud's segmentation was adopted after a long discussion that lasted for several decades. This segmentation can be simulated using 3-D CT images before surgery, or it can be visualized using fluorescent images with ICG during surgery. The caudate lobe is one of the most complicated segments of the liver, surrounded by other segments and landmark vessels, and anatomical resection of the caudate lobe requires proper understanding of its three components: the Spiegel lobe, the paracaval portion and the caudate process. Left trisectionectomy, anatomical resection of segment 8, ALPPS and procurement of right lateral liver grafts in LDLT are challenging for surgeons. Detailed knowledge of the liver's anatomical structure is important for safe completion of these technically demanding hepatectomies.

\section{Acknowledgements}

This work was supported in part by Grant-in-Aid for scientific research from the Ministry of Health and Welfare of Japan.

The authors acknowledge the valuable contribution of the following colleagues to the 19th annual meeting of Japanese Research Society of Clinical Anatomy: Junichi Shindoh, Hepatobiliary-Pancreatic Surgery Division, Department of Digestive Surgery, Toranomon Hospital; Masakazu Yamamoto, Department of Surgery, Institute of Gastroenterology, Tokyo Women's Medical University; Shouichi Satou, Department of Hepatobiliary-Pancreatic Surgery, Saitama Medical Center, Saitama Medical University; Takeaki Ishizawa, Department of Gastrointestinal Surgery, Cancer Institute Hospital, Japanese Foundation for Cancer Research; Kimitaka Kogure, Laboratory of Cell Physiology, Institute for Molecular and Cellular Regulation, Gunma University; Junji Yamamoto, Department of Surgery, National Defense Medical College; Minoru Esaki \& Yoji Kishi, Hepatobiliary and Pancreatic Surgery Division, National Cancer Center Hospital; Kuniya Tanaka, Department of Surgery, Teikyo University Chiba Medical Center, and Takashi Kokudo, Division of Gastroenterological Surgery, Saitama Cancer Center.

The authors give special thanks to Prof. Tatsuo Sato, President for Tokyo Ariake University of Medical and Health Science, for his instructive and beneficial comments on the sessions on liver anatomy.

All of the abstract of the 19th congress of Japanese Research Society of Clinical Anatomy, November 14 th, 2015, are going to be published in another journal [25].

\section{Disclosure Statement}

The authors declare no conflicts of interest.

\section{References}

1 Rex H: Beiträge zur Morphologie der Säugerleber. Morphol Jahrb 1888;14:517-616.

2 Cantlie J: On a new arrangement of the right and left lobes of the liver. J Anat Physiol 1898;32:4-10.

3 Hjortsjö CH: The topography of the intrahepatic duct systems. Act Anat (Basel) 1951;11:599-615.

4 Healey JE Jr, Schroy PC: Anatomy of the biliary ducts within the human liver: analysis of the prevailing pattern of branches and the major variations of the biliary ducts. Arch Surg 1953;66:599-616.

5 Couinaud C: Anatomic principles of left and right regulated hepatectomy: technics (in French). J Chir (Paris) 1954;70:933-966.

6 Takasaki K: Selection of operative procedure for primary hepatocellular carcinoma, complicated with liver cirrhosis. Criteria on control of volume in hepatic resection in consideration of security radicality and new developed anatomically systematized hepatic resection. Nihon Shokaki Geka Gakkai Zasshi 1986;19:1881-1889.

7 Cho A, Yamamoto H, Kainuma O, Nagata M, Takiguchi N, Shimada H, Soda H, Gunji H, Miyazaki A, Ikeda A: Extended left hepatectomy of the left and middle hepatic venous drainage areas along the anterior fissure. Am J Surg 2010;200:186-190. 
Sakamoto et al.: Clinical Anatomy of the Liver: Review of the 19th Meeting of the Japanese Research Society of Clinical Anatomy

8 Cho A, Okazumi S, Makino H, Miura F, Shuto K, Mochiduki R, Tohma T, Kudo H, Matsubara K, Gunji H, Yamamoto H, Ryu M, Ochiai T: Anterior fissure of the right liver - the third door of the liver. J Hepatobiliary Pancreat Surg 2004;11:390-396.

9 Kumon M: Anatomy of the caudate lobe with special reference to portal vein and bile duct. Kanzo (Liver) 1985; 26:1193-1199.

10 Nakamura S, Tsuzuki T: Surgical anatomy of the hepatic veins and the inferior vena cava. Surg Gynecol Obstet 1981;152:43-50.

11 Kogure K, Kuwano H, Fujimaki N, Makuuchi M: Relation among portal segmentation, proper hepatic vein, and external notch of the caudate lobe in the human liver. Ann Surg 2000;231:223-228.

12 Kogure K, Kuwano H, Yorifuji H, Ishikawa H, Takata K, Makuuchi M: The caudate processus hepatic vein: a boundary hepatic vein between the caudate lobe and the right liver. Ann Surg 2008;247:288-293.

13 Yamamoto J, Yamamoto H, Nishikawa M, Moriya T, Hatsuse K, Tsujimoto H, Ueno H, Hashiguchi Y, Hase K, Shinmoto H, Kaji T: Right-sided retrocaval approach using guidance via the lesser sac for Spieghel lobe resection. Surgery 2013;153:282-286.

14 Esaki M, Shimada K, Nara S, Kishi Y, Sakamoto Y, Kosuge T, Sano T: Left hepatic trisectionectomy for advanced perihilar cholangiocarcinoma. Br J Surg 2013;100:801-807.

15 Shindoh J, Mise Y, Satou S, Sugawara Y, Kokudo N: The intersegmental plane of the liver is not always flat tricks for anatomical liver resection. Ann Surg 2010;251:917-922.

16 Makuuchi M, Hasegawa H, Yamazaki S: Ultrasonically guided subsegmentectomy. Surg Gynecol Obstet 1985; 161:346-350.

17 Takayama T, Makuuchi M, Watanabe K, Kosuge T, Takayasu K, Yamazaki S, Hasegawa K: A new method for mapping hepatic segment: counterstaining identification technique. Surgery 1991;109:226-229.

18 Inoue Y, Arita J, Sakamoto Y, Ono Y, Takahashi M, Takahashi Y, Kokudo N, Saiura A: Anatomical liver resections guided by 3-dimensional parenchyma staining using fusion indocyanine green fluorescence imaging. Ann Surg 2015;262:105-111.

19 Kishi Y, Hasegawa K, Kaneko J, Aoki T, Beck Y, Sugawara Y, Makuuchi M, Kokudo N: Resection of segment VIII for hepatocellular carcinoma. Br J Surg 2012;99:1105-1112.

20 Kamiya J, Nagino M, Uesaka K, Sano T, Nimura Y: Clinicoanatomical studies on the dorsal subsegmental bile duct of the right anterior superior segment of the human liver. Langenbecks Arch Surg 2003;388:107-111.

21 Schnitzbauer AA, Lang SA, Goessmann H, et al: Right portal vein ligation combined with in situ splitting induces rapid left lateral liver lobe hypertrophy enabling 2-staged extended right hepatic resection in small-for-size settings. Ann Surg 2012;255:405-414.

22 Tanaka K, Endo I: ALPPS: short-term outcome and functional changes in the future liver remnant. Ann Surg 2015;262:e88-e89.

23 Kokudo T, Hasegawa K, Sugawara Y, Kokudo N: Pitfall of right lateral sector graft procurement: supraportal right posterior hepatic artery. Transplantation 2013;96:e89-e91.

24 Kokudo T, Hasegawa K, Arita J, Yamamoto S, Kaneko J, Akamatsu N, Sakamoto Y, Makuuchi M, Sugawara Y, Kokudo N: Use of a right lateral sector graft in living donor liver transplantation is feasible, but special caution is needed with respect to liver anatomy. Am J Transplant 2016;16:1258-1265.

25 Akita K: Abstracts presented at the 19th congress of Japanese Research Society of Clinical Anatomy on November 14th, 2015, at the University of Tokyo, Tokyo, Japan. Surg Radiol Anat 2016, in press. 